\title{
Epidemiologic Trends in Human Hepatitis A Virus Infection Stratified by Age between 2010 and 2018 in Cheonan, Korea
}

\author{
Jae-Sik Jeon and Jae Kyung Kim* \\ Department of Biomedical Laboratory Science, Dankook University College of Health Sciences, Cheonan 31116, Republic of Korea
}

Received: March 12, 2020 / Revised: May 28, 2020 / Accepted: June 1, 2020

\begin{abstract}
Although studies on Hepatitis A virus (HAV) were crucial in the establishment of the HAV infection prevention programs, no systematic investigation into HAV has been conducted since 1999. We retrospectively analyzed the data between January 2010 to December 2018 from all the patients who underwent HAV antibody tests at the Dankook University Hospital Health Care Center. Data were collected from 56,204 individuals. Overall, $34,834(62.0 \%)$ individuals from this cohort were positive for HAV antibodies and the annual rate of anti-HAV antibody positivity was highest in $2010(68.5 \%)$ and lowest in $2013(54.8 \%)$. The average decline in the antibody positivity rate was $0.62 \%$ per year, showing a statistically significant difference $(p<0.001)$. In the over 40 s age group, anti-HAV antibody positivity rates decreased from $89 \%$ in 2010 to $64 \%$ in $2018(p<0.001)$, with an annual decrease of $3.1 \%$. In the over $30 \mathrm{~s}$ age group, it decreased from $48.2 \%$ in 2010 to $34.7 \%$ in $2018(p<0.001)$, with an annual decrease of $1.82 \%$. This study shows that the antibody positivity rate is decreasing across age groups but given that HAV infection poses more significant risks in older patients it is important to expand the evaluations of the current and future antibody positivity rates for HAV in various age groups.
\end{abstract}

Keywords: Epidemiological monitoring, human Hepatitis A Virus, immunological surveillance, viral antibodies, viral diseases

\section{Introduction}

Hepatitis A is caused by the hepatitis A virus (HAV), and whose primary site of replication is the liver [1]. HAV transmission mainly occurs through the fecal-oral route. Insufficient sanitation and poor hygienic conditions lead to contamination of water and food, especially shellfish [2, 3]. Moreover, areas with an inadequate water supply and wastewater facilities and hygiene generally have high HAV prevalence [4-6]. In Korea, Hepatitis A was 867 in 2013, and it has continued to increase

\section{*Corresponding author}

Tel: +82-41-550-1451, Fax: +82-41-559-7934

E-mail: nerowolf2@dankook.ac.kr

○ 2020, The Korean Society for Microbiology and Biotechnology until 2018 [7].

HAV infections occurring before the age of 6 years are usually asymptomatic and resolve spontaneously, resulting in the generation of antibodies. However, the severity of this disease increases with age [8], and in older patients, inflammatory hepatitis may lead to rapid deterioration in hepatic function and death.

Anti-HAV antibodies (IgG) are generated in 60-90\% of individuals exposed to HAV. Hence, the rate of antiHAV antibody positivity in an age group could indicate the infection pattern of hepatitis A virus by age $[9,10]$. Due to the high economic growth in Korea that has resulted in improved living conditions and personal hygiene, the rate of anti-HAV antibody positivity in $20-30$ s young individuals has decreased from $60 \%$ to less 
than $10 \%$ over the past 25 years. Consequently, the risk of developing hepatitis A at an older age has increased [10].

Recent studies on hepatitis have focused on the genetics of hepatitis viruses. Moreover, epidemiological research has largely been restricted to hepatitis B and C with limited studies focusing on hepatitis A. No systematic investigation into HAV has been conducted since 1999, even though studies on hepatitis were crucial for establishing programs to prevent HAV infection. To this end, we examined the trend of total antibody tests in all ages for HAV at Dankook University Hospital Health Care Center in Cheonan, Korea, over a 9years period, from 2010 to 2018.

\section{Materials and Methods}

\section{Study design and setting}

We retrospectively analyzed data from all patients who underwent a total antibody test for HAV at Dankook University Hospital Health Care Center between January 2010 and December 2018 in Cheonan, Korea.

\section{Population}

All patients at the hospital health center were included, irrespective of age or sex. Patients who did not undergo HAV total antibody testing were excluded.

\section{Variables}

We conducted the study by setting the HAV total antibody test date, subject's age, sex, and antibody positivity as variables.

\section{Measurements}

For the total antibody test, anti-HAV antibody levels (total) (i.e., IgM and IgG) were evaluated with an ADVIA Centaur immunoassay system (Siemens, USA) and the HAV total reagents (Siemens Healthcare Diagnostics, USA) using a competitive chemiluminometric immunoassay. Anti-HAV IgM levels were evaluated with the ADVIA Centaur system and the IgM HAV reagents (Siemens Healthcare Diagnostics) using an antibody capture microparticle chemiluminometric immunoassay. When deciding the positivity of the antibody, the cut-off for the reactivity of anti-HAV (total) was 20.0 IU (international unit)/L, and for anti-HAV IgM reactivity, a signal-to-cut-off value of $1.2 \mathrm{~S} / \mathrm{Co}$ was considered.

\section{Ethical considerations}

The present study was approved by the institutional review board (IRB) of the Dankook University (IRB Approval No: 2019-02-002).

\section{Statistical methods}

Data were analyzed for the HAV total antibody test results using the $\mathrm{R}$ statistical program (version 3.3.3, Comprehensive $\mathrm{R}$ Archive Network; https://www.rproject.org) and presented as the means (with standard deviation) and medians (with range). The chi-square test was used to analyze categorical data.

\section{Results}

The characteristics of the study cohort are summarized in Table 1 . The mean $\pm \mathrm{SD}$ age of the 56,204 individuals was $41.9 \pm 11.6$ years. Correct to 32,568 (57.9\%) were men, and 34,834 (62\%) had HAV antibodies (20,548 men and 14,286 women). The positivity rate was significantly higher in men than in women $(p<0.001)$.

The annual rate of anti-HAV antibody positivity was highest in 2010 at $68.5 \%$ and lowest in 2013 at 54.8\%. The rate of antibody positivity decreased by $0.62 \%$ per year on average, showing a statistically significant difference $(p<0.001)$. The highest and lowest mean age of those positive for HAV antibodies was 45.0 years (in 2018) and 39.8 years (in 2013) (Table 2).

In the age-specific analysis, the average rate of antibody positivity was found to be highest in those 60 s age group (99.9\%), and lowest in those aged 10-29 years (16.7\%) (Fig. 1). No significant change was observed in the rate of antibody positivity among those over 60 years of age during the 9-year period. However, among those in the 40 s age group, this rate decreased from $89 \%$ in

Table 1. General characteristics of study participants.

\begin{tabular}{cccc}
\hline & Number & $\begin{array}{c}\text { Proportion/ } \\
\text { Rate }\end{array}$ & $\begin{array}{c}\text { Average age } \\
(\mathrm{y})^{\mathrm{a}}\end{array}$ \\
\hline Total & 56,204 & $100.0 \%$ & 41.9 \\
Male & 32,568 & $57.9 \%$ & 42.9 \\
Female & 23,636 & $42.1 \%$ & 40.6 \\
\hline Positive & 34,834 & $62.0 \%$ & 47.2 \\
Negative & 21,370 & $38.0 \%$ & 33.4 \\
\hline
\end{tabular}

${ }^{a}$ Age range, 15.8-92.4 y 
Table 2. Prevalence of antibody positivity according to the year and age group.

\begin{tabular}{|c|c|c|c|c|c|c|c|c|c|c|}
\hline \multicolumn{2}{|l|}{ Year } & 2010 & 2011 & 2012 & 2013 & 2014 & 2015 & 2016 & 2017 & 2018 \\
\hline \multicolumn{2}{|c|}{ No. of participants } & 11,153 & 9,275 & 5,571 & 7,972 & 4,961 & 5,392 & 4,382 & 4,187 & 3,311 \\
\hline \multicolumn{2}{|c|}{ No. showing positive findings } & 7,639 & 6,116 & 3,308 & 4,369 & 2,993 & 3,189 & 2,673 & 2,494 & 2,053 \\
\hline \multicolumn{2}{|c|}{ Rate of positivity } & $68 \%$ & $66 \%$ & $59 \%$ & $55 \%$ & $60 \%$ & $59 \%$ & $61 \%$ & $60 \%$ & $62 \%$ \\
\hline \multicolumn{2}{|c|}{ Average age (y) } & 41.2 & 41.5 & 40.9 & 39.8 & 41.6 & 43.3 & 44.3 & 44.0 & 45.0 \\
\hline & $10-29 y$ & $14 \%$ & $16 \%$ & $18 \%$ & $15 \%$ & $16 \%$ & $13 \%$ & $20 \%$ & $24 \%$ & $21 \%$ \\
\hline HAV antibody & $30-39 y$ & $48 \%$ & $46 \%$ & $38 \%$ & $36 \%$ & $36 \%$ & $32 \%$ & $32 \%$ & $32 \%$ & $35 \%$ \\
\hline positivity rate & $40-49 y$ & $89 \%$ & $88 \%$ & $84 \%$ & $84 \%$ & $84 \%$ & $78 \%$ & $74 \%$ & $67 \%$ & $64 \%$ \\
\hline according to age & $50-59 y$ & $98 \%$ & $98 \%$ & $99 \%$ & $98 \%$ & $98 \%$ & $97 \%$ & $97 \%$ & $96 \%$ & $95 \%$ \\
\hline \multirow[t]{2}{*}{ group } & $60-69 y$ & $100 \%$ & $100 \%$ & $100 \%$ & $100 \%$ & $100 \%$ & $100 \%$ & $100 \%$ & $100 \%$ & $100 \%$ \\
\hline & $70-99 y$ & $100 \%$ & $100 \%$ & $100 \%$ & $100 \%$ & $100 \%$ & $100 \%$ & $100 \%$ & $99 \%$ & $99 \%$ \\
\hline
\end{tabular}

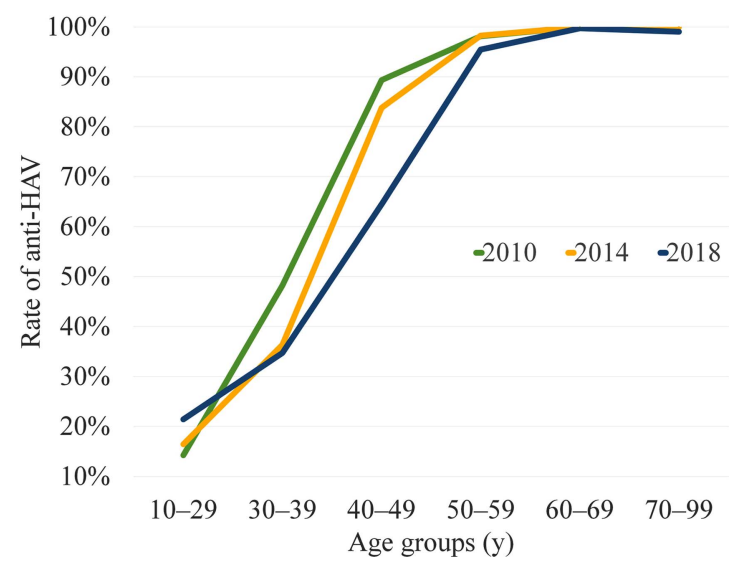

Fig. 1. Anti-HAV antibody positive rate according to age. The age range is 15.8-82.3 and includes three years in this graph.

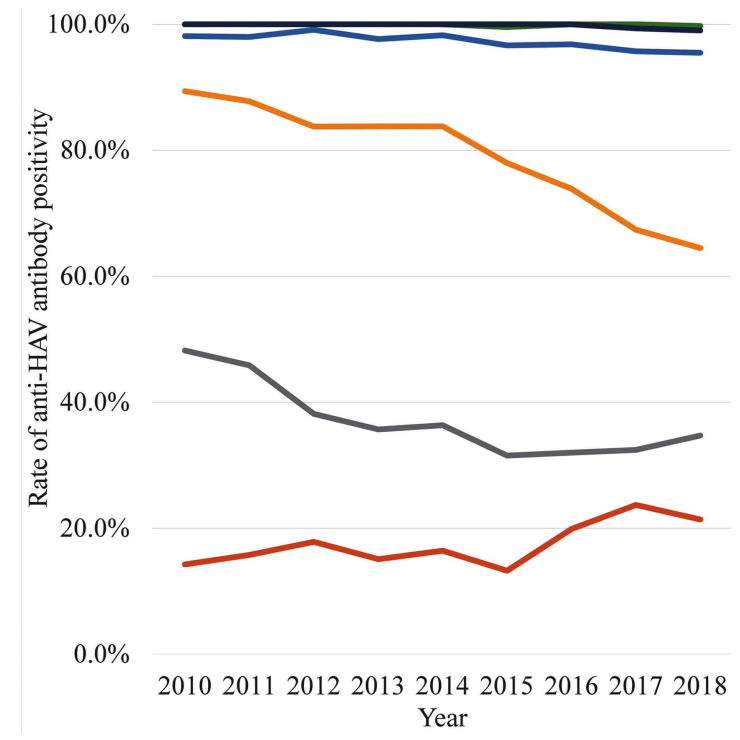

Fig. 2. Anti-HAV antibody positive rate according to period with age group. Each line represents anti-HAV antibody positive rate according to age group.
2010 to $64 \%$ in 2018 ( $p<0.001)$, with an annual decrease of $3.1 \%$. Further, among those in the 30 s age group, it decreased from $48.2 \%$ in 2010 to $34.7 \%$ in 2018 $(p<0.001)$, with an annual decrease of $1.82 \%$ (Fig. 2).

\section{Discussion}

In the study by Lee et al. [11], men accounted for $60 \%$ of those showing positivity for anti-HAV antibodies, and Ly et al. also [12] reported a significantly higher rate in men. This is consistent with our study, in which the rate of positivity was found to be 1.44-times higher in men. The prevalence of HAV has been reported to be influenced by socio-demographic factors such as residence, family size, and socioeconomic status [13], but further study is needed for differences in infection rates by gender.

This study analyzed the positivity rate of anti-HAV antibodies in a regional unit over time. In the present study, the mean age of participants was $41.9 \pm 11$ years, higher than that in studies from Kim et al. [14], Laurence [15], and Ly et al. [12] (25, 33, and 36 years, respectively). This can be thought of as obtaining an anti-HAV antibody at an older age, when symptoms may be more severe. This result is thought to be due to the lower anti HAV antibody positivity rate in the relatively young age group of 10-39 years old.

The trend of annual antibody positivity showed a significant gradual decrease in our study, with the highest reduction observed among those in the 30s and 40s (decrease of $15 \%$ and $25 \%$, respectively). This was similar to the findings of Lee et al. [16], who reported a downward trend in their 2009 study, and to those of Kim 
et al. [17], who also reported a decrease in HAV antibody positivity rate among those in the $20 \mathrm{~s}$ and $40 \mathrm{~s}$ in their 2017 study.

The prevalence of hepatitis A varies according to living conditions, hygiene, and economic status. Infections have been reported to occur in children and adolescents in developing and developed countries, and in adults in developed countries [18]. In this study, the anti-HAV antibody positivity rate among those aged $10-29$ years was lowest in 2015 (13\%) and remained lower than $20 \%$ until 2018. In addition, it remained low at $35 \%$ among those in their $30 \mathrm{~s}$ and $64 \%$ among those in their $40 \mathrm{~s}$, thus lowering the overall positivity rate from $68.5 \%$ to 54.8\%. Kim et al. [19], in their 2006 report, predicted that teenagers and those in the $20 \mathrm{~s}$ age would have an anti-HAV antibody positivity rate of less than $20 \%$, and those in the 30 s would have a prevalence of $70 \%$.

Our study has some limitations. First, we collected a large size of data were sourced from a single center, our findings may not be representative of the real-life situation in Korea, and further analyses using data from multiple centers are warranted. Second, we could not determine whether the rate of HAV antibody positivity had reduced because of the decrease in incidence due to advances in the medical system because comparisons with the hepatitis A prevalence rate could not be made.

Wang et al. [20] reported an increase in the rate of antibody positivity due to active vaccination in China, and Sanguanmoo et al. [21] reported lower rates of antiHAV antibody positivity in Thailand that have been reported in the past. Further, the severity of hepatitis A increases with age, and the disease may be fatal in older adults. Moreover, adults with hepatitis A may develop ectopic liver failure may or show an atypical clinical course, such as recurrent hepatitis, persistent hepatitis, or cholestatic hepatitis [22]. This study shows that the antibody positive rate by age group is decreasing. Since hepatitis A causes greater damage in adults, more extensive research is needed on the current and future positivity rates of $\mathrm{HAV}$ antibodies over time. We recommend hepatitis A vaccination in young adults to reduce the risk of $\mathrm{HAV}$ infection.

\section{Conflict of Interest}

The authors have no financial conflicts of interest to declare.

\section{References}

1. Nainan OV, Xia G, Vaughan G, Margolis HS. 2006. Diagnosis of hepatitis A virus infection: a molecular approach. Clin. Microbiol. Rev. 19: 63-79.

2. Cristina J, Costa-Mattioli M. 2007. Genetic variability and molecular evolution of Hepatitis A virus. Virus Res. 127: 151-157.

3. Hadler SC, Webster HM, Erben JJ, Swanson JE, Maynard JE. 1980. Hepatitis A in day-care centers. A community-wide assessment. New Eng. J. Med. 302: 1222-1227.

4. Ouardani I, Turki S, Aouni M, Romalde JL. 2016. Detection and molecular characterization of hepatitis A virus from Tunisian wastewater treatment plants with different secondary treatments. Appl. Environ. Microbiol. 82: 3834-3845.

5. Jacobsen KH, Koopman JS. 2005. The effects of socioeconomic development on worldwide hepatitis $A$ virus seroprevalence patterns. Int. J. Epidemiol. 34: 600-609.

6. Ouardani I, Manso CF, Aouni M, Romalde JL. 2015. Efficiency of hepatitis $A$ virus removal in six sewage treatment plants from central Tunisia. Appl. Microbiol. Biotechnol. 99: 10759-10769.

7. Korea Ministry of Health \& Welfare, Korea Centers for Disease Control and Prevention. Infectious Diseases Surveillance Yearbook, pp. 21. 2018. Publication Number: 11-1352159-000048-10.

8. Cho KY. 2010. Hepatitis A. Korean J. Pediatr. Gastroenterol. Nutr. 13: S70-77.

9. Weitz M, Siegl G. 1985. Variation among hepatitis A virus strains. I. Genomic variation detected by $\mathrm{T} 1$ oligonucleotide mapping. Virus Res. 4: 53-67.

10. Song YB, Lee JH, Choi MS, Koh KC, Paik SW, Yoo BC, et al. 2007. The age-specific seroprevalence of hepatitis $A$ virus antibody in Korea. Korean J. Hepatol. 13: 27-33.

11. Lee A, Lim HS, Nam CM, Song SM, Yoon HR, Lee KR. 2009. An epidemiological analysis of hepatitis $A$ virus serologic markers during the recent four years in Korea. Korean J. Lab. Med. 29: 563569.

12. Ly KN, Klevens RM. 2015. Trends in disease and complications of hepatitis A virus infection in the United States, 1999-2011: a new concern for adults. J. Infect. Dis. 212: 176-182.

13. Altınkaynak S, Selimoğlu MA, Ertekin V, Kılıçaslan B. 2008. Epidemiological Factors affecting hepatitis $A$ seroprevalence in childhood in a developing country. Eurasian J. Med. 40: 25-28.

14. Kim DH, Park KJ, Kim SH, Cho SB, Lee WS, Park CH, et al. 2007. Clinical characteristics of patients with acute hepatitis $A$ in Gwangju-Chonnam province for recent 10 years. Korean J. Med. 72: 131-137.

15. Laurence JC. 2005. Hepatitis A and B immunizations of individuals infected with human immunodeficiency virus. Am. J. Med. 118: $75 S-83 S$.

16. Lee A, Lim HS, Nam CM, Song SM, Yoon HR, Lee KR. 2009. An epidemiological analysis of hepatitis $A$ virus serologic markers during the recent four years in Korea. Korean J. Lab. Med. 29: 563569.

17. Kim KA, Lee A, Ki M, Jeong SH. 2017. Nationwide seropositivity of 
Hepatitis A in Republic of Korea from 2005 to 2014, before and after the outbreak peak in 2009. PLoS One 12: e0170432.

18. Brundage SC, Fitzpatrick AN. 2006. Hepatitis A. Am. Fam. Physician. 73: 2162-2168.

19. Kim JH. 2008. Recent epidemiological status and vaccination of Hepatitis A in Korea. J. Korean Med. Assoc. 51: 110-118.

20. Wang H, Gao P, Chen W, Bai S, Lv M, Ji W, et al. 2019. Changing epidemiological characteristics of hepatitis $A$ and warning of anti-HAV immunity in Beijing, China: a comparison of prevalence from 1990 to 2017. Hum. Vaccin. Immunother. 15: 420-425.

21. Sa-nguanmoo $P$, Posuwan $N$, Vichaiwattana $P$, Vuthitanachot $V$, Saelao S, Foonoi $M$, et al. 2016. Declining trend of hepatitis $A$ seroepidemiology in association with improved public health and economic status of Thailand. PLoS One 11: e0151304.

22. Tong MJ, el-Farra NS, Grew MI. 1995. Clinical manifestations of hepatitis A: recent experience in a community teaching hospital. J. Infect. Dis. 171: S15-S18. 